\title{
Food Labeling Regulations in South Asian Association for Regional Cooperation (SAARC) Countries: Benefits, Challenges and Implications
}

\author{
Sayed Mohammad Naim Khalid* \\ National Medicine and Food Board- Ministry of Public Health, 10 Zone, Wazir Akbar Khan, Kabul, Afghanistan
}

\section{A R T I C LE INFO}

Article history:

Received 14 July 2014

Accepted 22 September 2014

Available online, ISSN: 2148-127X

Keywords:

Food labeling

Regulations

Harmonization

Nutrition

\begin{abstract}
A B S T R A C T
Food labels describe the content of a food and are intended to guide the consumer in food selection. The nutrition information provided must be in consistency with legal requirements and dietary recommendations. Selection of the specific nutrients or food components to be listed should further take into account label space, the analytical feasibility of measuring the particular nutritional component within the food matrix, and the relative costs of such analyses. Information provided on labels should be truthful and not mislead consumers. At the same time, labeling regulations should provide incentives to manufacturers to develop products that promote public health and assist consumers in following dietary recommendations. In some countries some segments of the population benefit from information about the composition of foods. In such cases, countries should consider the need to provide for appropriate labeling and its presentation relative to existing regulations. Different approaches and legal requirements have been established. These create difficulties in developing and harmonizing labels, which have broad international applications. For these reasons, the Codex Guidelines on food labeling play an important role to provide guidance to member countries when they want to develop or update their national regulations and to encourage harmonization of national with international standards. These Guidelines are based on the principle that no food should be described or presented in a manner that is false, misleading or deceptive. Exchange of information at the regional and sub-regional level is important, as each country can learn from the experience of others and regional co-ordination and co-operation can be developed.
\end{abstract}

\section{Introduction}

Labels on food packages aim to promote and protect consumer's interests by providing information on various product attributes and nutrition contents of the product so that the consumers can make informed dietary choices (Kumar, 2011; Zaidi and Bakhtiar Mohammad, 2011). The role of food labeling in purchase decision has widely been empirically researched across the world which indicate that consumers look at labels and that label information affects their purchase decision (Kumar, 2011; Baltas, 2001; Golan et al., 2001; Cowburn and Stockley, 2005). The Guideline Daily Amount is viewed by the consumers during shopping and it positively affects their buying behavior. Consumer's preference towards a brand is directly affected by self-control and temptation (Zaidi and Bakhtiar Mohammad, 2011).

Issues of food and nutrition labeling are becoming more and more important globally in view of diet-related diseases, such as diabetes, coronary heart disease and cancer, which are fast becoming a burgeoning threat to public health. Besides this, the labeling of pre-packaged foodstuffs is key to foreign food trade. As such, debates are progressive, ongoing and inconclusive regarding what goes into the label, the format, verifiability, size, impact and authority. Indeed, different groups have argued for their concerns to be labeled: ingredients, residues, animal welfare, allergens, environmental impact, nutrition, ethics and more (Lang, 2006; Cheftel, 2004).

At the moment, many international, scientific and research organizations are working harmoniously to try to eliminate the differences in interests and food regulations among countries. These organizations include, among others, the Codex Alimentarius Commission (CAC), the World Trade Organization (WTO), the International Standardization Organization (ISO) and organizations such as the Global Harmonization Initiative (GHI) and the International Union of Food Science and Technology (IUFoST) (Lelieveld and Keener, 2007).

Best efforts by international organizations to enhance global harmonization of food standards are of unprecedented importance in public health and world food trade. This review discusses the current status of food and nutrition labeling regulations in Southeast Asia and the discrepancies that exist in this regard. It also describes the Common Principles and Guidelines for harmonizing food labeling regulations, which food experts in the region have drafted and finalized, and 
highlights the benefits, challenges and implications that lie ahead for member states, the food industry and consumers.

\section{Brief Overview On Saarc Countries}

According to Ali and Talukder (2009) South Asia, with more than 1.4 billion people, is one of the most densely populated regions in the world. Population density is 275 people per sq. $\mathrm{km}$ which is six times higher than that of the world average population density. This region is the home of 23 percent of the world's population comprising an area of only 3.8 percent of the total global land. Considering the market-size in terms of population, SAARC is one of the largest economic blocs in the world. This region covers almost 67 percent of the low income population of the world economy.

However, as measured in 2013 according to International Monetary Fund (IMF) by gross domestic product (GDP) as well as per capita income, the size of the economy of this region is very small compared to the rest of the world. It accounted for 3.189 percent of world's GDP. Similarly, in terms of shares in the world trade, South Asia is considered as an insignificant region which accounts only for 1.70 percent of total global trade.

Considering the size of land area, population and economy, India is by far the largest country in South Asian region; while Pakistan and Bangladesh are the second and third largest country respectively. It is argued that, because of their size, these three economies are of crucial importance for successful regional integration and cooperation; and more importantly, India and Pakistan would be the dominant states of any formal regional integration agreements (Das, 2007; Behera, 2008). Bhutan, Maldives and Nepal are very small economies in the region. The important fact is that Bhutan and Nepal are land-locked while Maldives is an island. Under the World Bank designated category, amongst the seven countries, four economies namely Bangladesh, Bhutan, Maldives and Nepal, are least developed countries (LDCs); and India, Pakistan, Sri Lanka are considered developing countries. On the basis of income Bhutan, Maldives and Sri Lanka are lower-middle-income countries; and Bangladesh, India, Nepal and Pakistan are low-income countries (Das, 2007; World Bank, 2007). Despite the region has been performing steadily for the last two decades in terms of economic growth and other criteria, it has still remained one of the poorest regions in the world.

In 2007 Afghanistan has become a member of SAARC. As this country is a new member and its involvement is still insignificant in SAARC, this review hasn't included Afghanistan in food regulation analysis.

\section{Labeling Requirenments In Saarc Countries}

\section{Afghanistan}

Afghanistan is SAARC member country which does not have food law yet and there are no specific legal requirements for food product labeling.

\section{Bangladesh}

Bangladeshi regulations stipulate that all imported food products must be labeled to indicate the country of origin, quantity or weight, ingredients, and dates of manufacture and expiration. Labeling may be in English or Bangla (Bengali) language. Baby food and foods containing milk must have the product's composition, the percentage of various ingredients, and the statement "There is no alternative to breastfeeding" must be printed in Bangla on each container of baby food that contains cream. For all food and beverage products (except for wine and liquor), including those that are imported, the dates of manufacture and expiration must be clearly printed. All such printing must be on the containers; separately printed labels pasted on the containers are not acceptable.

There is no separate law regulating the labeling requirements for food and agricultural commodities in Bangladesh. The labeling of domestically produced and packaged condensed milk and dried milk powder are prescribed in Bangladesh's Pure Food Rules (1967) promulgated by the Department of Health. The government was granted the power to implement these rules via the Bangladesh Pure Food Ordinance of 1959. Although these rules detail the provisions on food poisoning, food coloring, preservatives in food, etc., there is no mention of the labeling requirements for packaged food items, except for condensed milk and dried milk powder.

Currently, the main legal instrument that regulates the labeling requirements of imported food products is the Import Policy Order 2009-12. In light of requirements in the World Trade Organization (WTO) Agreement on Technical Barriers to Trade (TBT) and the Agreement on the Application of Sanitary and Phytosanitary (SPS) Measures, the Product Labeling Policy was introduced in 2006 to ensure that no barriers are created for the importation and exportation of goods, and to ensure that imported products have proper labels. The policy refers explicitly to international labeling standards to be observed in 15 sectors. In all cases of import, the country of origin has to be mentioned clearly on goods, packages and containers. The name, address and taxpayer identification number (TIN) are required to be inscribed or printed in indelible ink on at least 2 percent of the largest packet, cover, can, sack pack, wooden box or other packets containing the imported goods. For imports of all kinds of food and beverages, the dates of manufacture and expiration and net weight must clearly be embossed on each container or package. Separately printed labels are not acceptable. Imports of wine and liquor do not require an expiration date.

\section{Bhutan}

Bhutan had established a National Food Inspectorate under the Bhutan Agriculture and Food Regulatory Authority (BAFRA) of the Ministry of Agriculture. According to Food and Nutrition Security Policy of the Kingdom of Bhutan, 2012 the food labeling systems must comply with proper national requirements and enable consumers to make informed food choices based on labeling information. The Food Act of Bhutan of 2005 provides protection to human health through trade of food in the Kingdom of Bhutan. 


\section{India}

According to a survey 41 percent of Indians check nutritional labels when purchasing a product for the first time. Interestingly, consumers are most concerned with the nutritional information on food labels when buying food products for their children (Kumar, 2011).

The disclosure of information on food labels in India are primarily governed by the Prevention of Food Adulteration Act, 1954, which has primarily focused on the basic information of the product on the food labels and put less emphasis on health and nutritional information to be given on the food labels. However, recent amendments on packaging and labeling of food under part VII of the Prevention of Food Adulteration Rules, 1955 has mandated to disclose the health and nutritional claims on the food labels along with basic information. The new integrated Food Safety and Standards Act (FSSA), 2006 in Chapter IV, paragraph 23 clearly states that no person shall manufacture, distribute, sell or expose for sale, or dispatch or deliver to any agent or broker for the purpose of sale any packaged food product which is not marked and labeled in the manner as may be specified by regulation.

The Food Safety and Standards (packaging and labeling) Regulations, 2011 require that every package of food shall carry the following information on the label: (1) The trade name or description of the food item, (2) list of ingredients, except for single ingredient foods, (3) nutritional Information, (4) Veg and Non veg declaration.

\section{Nepal}

In Nepal the Food Act, 1966 is a legal document to protect food consumers from food safety problems. There are, however, general regulations on advertising goods and services in the Food Act of 1966 and in the Consumer Protection Act of 1997. Under the Food Act of 1966: "Clause 4. Food products cannot be sold through misleading activities".

Under the Consumer Protection Act of 1997: "Article 10. Actions which must not be take in respect to consumer goods or services: No one shall take or instigate others to take any of the following actions in respect to any consumer good or service, "To engage in unfair trading practices in such a manner as to make false or misleading publicity or advertisements relating to the use, usefulness, or efficacy of any consumer good or service".

The labeling requirement for food commodities has been further described in Food Rules, 1970. The chapter 6 of the Food Rules, 1970 describes, in detail, the labeling requirement as mentioned below:

- No packed food shall be sold or kept for sale unless and until a label is put on the wrapper of container of that food.

- The description to be specified in a label shall be in the Nepali or English language. The description may also be specified in another language, in addition to these two languages, if one so wishes.

- A person who has a duty to act in accordance with this Rule shall not overwrite, alter or deface or erase the label put in accordance with these Rules.
There is no specific mention regarding the following aspects of label of packed foods:

- Method of consumption and any side effects of the product.

- $\quad$ Price of product.

- Registration number of manufacturer.

- Composition of products.

- Standard mark of certification if given to the product.

- Products guarantee and guarantee time limit of products like electric, electronics hardware and machinery parts.

- Preventive and security measures necessary for any inflammable and hazardous.

The labeling requirements are same for domestic and imported food commodities.

\section{Pakistan}

The Customs Department's primary functions are: ensure that imported foods meet Pakistan's labeling and shelf-life requirements prevent imports on the list of banned items, and assess appropriate import tariffs.

Imported food products, including ingredients, must have at least 50 percent of their original shelf life remaining at the time of importation - calculated from the date of filing the "Import General Manifest" (IGM) in accordance with the Customs Act of 1969. The Labels are required to be English or Urdu languages.

Packages or containers must also indicate:

- The date of manufacture and date of expiration,

- That the contents are free from pork and pork products,

- $\quad$ That the contents are fit for human consumption and that any animal product was obtained from an animal slaughtered according to 'Halal' requirements,

- That import of edible oils is on the basis of landed weight and landed quality.

- That packing may not contain any word or inscription of a religious connotation or any obscene picture that may offend the religious feeling of any sect, class or group in Pakistan.

The production and expiration dates must be printed in English, using either words and/or numbers.

Standard U.S. bar-code labels alone are generally not acceptable as they lack printed production and expiration dates, as required by law.

Stickers, which contain the required printed dates of manufacture and expiration, should be affixed to the standard U.S. labels prior to shipment.

The coded "best before use date" is not considered to be an acceptable expiration date. In the past, several cargoes containing items without printed production and/or expiration dates were held by Customs until stickers with production and expiration dates certified by the Pakistani High Commission in the United States could be affixed to each individual item. 
Pakistan does not have any special or additional requirements based on the country of origin for any food product. In the event there is a worldwide alert for a product from a particular origin, Pakistan will notify the appropriate country and trade organizations of any changes in its import requirements. Authorities strictly enforce label requirements and do not grant exceptions. They are authorized to reject or to destroy any cargo with improper labels. In case of food items containing artificial flavoring substances, the label may not declare the chemical names of the flavors, but in the case of natural flavoring substances or nature-identical flavoring substances, the common name of flavors, including whether natural or synthetic, shall be mentioned on the label.

Pakistan does not require nutritional content to be listed on product labels but generally accepts U.S. Food and Drug Administration (FDA) regulations as guidelines. Pakistan Standards and Quality Control Authority regularly update its guidelines, based on Codex and FDA revisions.

\section{Sri Lanka}

The Food (Labeling \& Advertising) Regulations 2005 is applicable to all prepackaged food offered for sale or advertised for sale in Sri Lanka. The regulations specify, in terms of content, language, letter size and format, the information that the label should carry. The label shall be affixed on the main panel of the package or container of the food indelibly printed or painted or affixed. Foods that contain genetically modified raw materials should carry labels that state that fact. This regulation came into effect from 01.01.2007. Sri Lanka Customs, uses English as the key commercial language therefore facts presented in the labels should best be in English.

The Food Act comes under the purview of the Ministry of Health and it covers also labeling. Food labels should carry the common name of the contents in 2 of the following 3 languages English, Sinhalese and Tamil. Permission may be obtained to affix labels to fulfill this need.

The Consumer Affairs Authority has labeling regulations that requires the following as a must: Production and Expiry dates, Batch numbers and the Retail Price.

On 19.01.2005 the Ministry updated regulations for implementation. The "Food Labeling and Advertising regulations 2005" requires conformity to the following requirements in the labels.

- Country of Origin

- Date of Manufacturing, expiry and batch number.

- In the case of bulk supplies re-packed, the date of such re-packing.

- Declare nutrient claims only with prior approval.

- Claims on disease curing properties or cholesterol free, low sugar, etc. should conform to the parameters prescribed in the Food Act.

- Additives and Coloring should be identified with INS numbers (International Numbering System).

\section{Discrepancies In Food Regulations And Their Consequences}

As seen above, the regulations that govern food and nutrition labeling vary widely across countries in the region. These variations may be attributed to the use of different International Guidelines when preparing national regulations, and varying administrative systems which are based on many factors including, but not limited to, historical, political, cultural and economic. Table 1 summarizes the discrepancies that exist in nutrition labeling legislation, profiling and formatting in Southeast Asia countries. Due to the differences in regulations between nations, food products are tested and re-tested as they move from one country to another. The time and costs involved at least delay the availability of desirable products and, in worst cases, products do not reach the market at all (Lelieveld and Keener, 2007).

Universally acceptable manufacturing and marketing of products would simplify import and export procedures and, therefore, reduce hurdles in cross-border trade of food. This requires that food legislation and regulations have to be harmonized regionally and internationally. Knowing this, the food experts in the Southeast Asia region have drafted and finalized the Guiding Principles for Food Control Systems, which include the regional requirements for the labeling of pre-packaged foodstuffs (ASEAN, 2005).

Member countries are encouraged to follow these Guidelines when preparing or modifying their national food and nutrition regulations. The Guidelines are based on Codex Alimentarius standards, codes and related texts which are recognized and endorsed in WTO's Agreements on the application of Sanitary and Phytosanitary Measures (SPS) and Technical Barriers to Trade (TBT). In this context, when a country employs Codex standards, its measures are presumed to be consistent with the provisions of WTO's SPS and TBT Agreements (FAO/WHO, 2006; WTO, 2007).

\section{Harmonisation Of Food Labelling Regulations In The Region}

The Common Principles and Requirements for the Labeling of Pre-packaged Foodstuffs, which experts have established, provide the scope, definitions and rules for the labeling of processed food. The clearer and simpler the rules, the more likely they are to be properly implemented in all member countries. The generic labeling requirements are adopted from the Codex General Standard for the Labeling of Pre-packaged Foods (Codex Stan 1-1985; Rev. 1-1991) (CAC, 2008). They include the name of the product, a list of ingredients, the net contents or net weight, the name and place of business of the manufacturer, packer or distributor, date marking, instructions for storage and use, and nutrition information as elaborated below.

The name of the food means a specific designation or description of the foodstuff to indicate its true nature to the consumer. If the food has undergone processing or its physical condition has changed, this information should 
be added to the name of the food product to avoid confusion. A coined, fanciful brand name or trade mark that is not false or misleading may be given next to the name of the food in the principal display panel. Nevertheless, these should not be used to replace the name of the product.

A list of ingredients. Food ingredients and other substances can cause allergies or intolerances in some consumers. For this reason, all ingredients, including those obtained through genetic modification and ionizing radiation, must be listed on the label. The ingredients must also be identified by their common or usual names to help consumers identify the ones that they are allergic to or want to avoid for other reasons. The ingredient that is present in the largest amount, by weight, must be listed first. Other ingredients must follow in descending order according to weight as recorded at the time of their use in the manufacture of the food. In general, the following ingredients, known to cause allergies in some people, should always be declared: cereals containing gluten (e.g. wheat, rye, barley, oat, spelt or their hybridized strain), crustaceans, eggs and egg products, fish and fish products, peanuts and soybeans, milk and milk products (lactose included), tree nuts and nut products, and Sulphites $\left(\mathrm{SO}_{2}\right)$ in concentrations of $10 \mathrm{mg} / \mathrm{kg}$ or more.

Net contents and drained weight. The net quantity of food should be expressed in metric units of mass, namely weight for solid foods, volume for liquid foods and weight or volume for semi-solid or viscous foods. For solid foods sold in liquid media, the drained net weight must be declared.

Name and address of the manufacturer. The name and address of the manufacturer, or packer or distributor or owner of rights of manufacture or brand owner, should be given in the case of food of local origin. For imported food, the name and address of local importer and/or distributor and the country of origin are required. When a food undergoes processing in the second country, which changes its nature, the country in which the processing is performed shall be considered to be the country of origin for the purposes of labeling.

Date marking. The manufacturing date and the date of minimum durability of the food (best before or use-by date) must be clearly marked on the label. "Best before" means the date which signifies the end of the period under any stated storage conditions during which the product will remain fully marketable and will retain any specific qualities for which claims have been made. Beyond the "Best-before" date, the food may still be perfectly satisfactory. Conversely, Use-by Date, or Recommended Last Consumption Date or expiration date, connotes the date which signifies the end of the estimated period under any stated storage conditions, after which the product probably will not have the quality attributes normally expected by the consumer. After this date, the food should not be regarded as marketable. Depending on how long the food can keep, the Best before or Use-by date can be expressed by the day and the month, the month and year, or the year alone.

Storage instructions. Any special conditions necessary for proper storage of the food must be clearly stated on the label.

Instructions for use, including reconstitution. They are required when it would be impossible to make appropriate use of the food in the absence of such instructions.

Nutrition information. This information is equally important on food packaging as elaborated below.

\section{Regional Requirements For Nutrition Labelling}

The Regional Requirements for nutrition labeling are formulated based on the Codex Guidelines for Nutrition Labeling (CAC/GL 2-1985), and the Codex Guidelines on Use of Nutrition and Health Claims (CAC/GL 23-1997) (CAC, 2009a; CAC; 2009b).

Under the Regional Guidelines, nutrition labeling is voluntary, although it becomes compulsory when a nutrition or health claim is made in the labeling, presentation or advertising of a foodstuff or when vitamins or minerals are voluntarily added to food. In general, the regional requirements for nutrition labeling are as follows:

- The energy value and the amounts of protein, fat and carbohydrates must be declared when nutrition or health claims are made on food packaging.

- Information about energy and nutrients must be presented clearly, legibly and indelibly.

- Energy values must be expressed in $\mathrm{kJ}$ and kcal, and the amounts of protein, carbohydrate and fat in grams, while the amounts of vitamins and minerals should be expressed in metric units and/or as a percentage of the Codex Nutritional Reference Values.

- Energy values and the amounts of all the nutrients should be given per $100 \mathrm{~g}$ or per $100 \mathrm{ml}$ or per package, if the package contains only a single portion, or per serving as quantified on the label or per portion provided that the number of portions contained in the package is stated.

- Food intended for export should be labeled in English and/or in a national language for the country to which the food is marketed aside from voluntary nutrition labeling, the Regional Guidelines allow nutrient content, nutrient comparative and nutrient function claims to be made on food packaging in member countries, provided they meet the minimum criteria set by the Codex Alimentarius. In addition, claims indicating food grading or quality, such as "organic" or religious and ritual preparation of food (halal or kosher), may be used on the label.

In this regard, a symbol or logo for organic, halal or kosher, recognized by food safety and quality authorities, should be included on the label. The Regional Guidelines put emphasis on meaningful claims. To give an example, any comparative claim must clearly indicate the foods being compared. In addition, such a claim should not imply that a product is superior to any other existing product of the same kind without giving scientific substantiation for the claim.

Where possible, the food manufacturers are required 
to state the importance of a diversified and balanced diet, and never imply that ordinary foods are nutritionally inadequate. Misleading claims are prohibited; for example, claims about the absence of beef or pork or lard or their derivatives, or added alcohol when the food does not contain such ingredients or when such ingredients are not permitted. Moreover, reduction of disease risk claims and medicinal and/or therapeutic claims, which imply that a food can prevent, treat or cure a human disease, are prohibited. Currently, four countries permit reduction of disease risk claims in the region, namely Indonesia, Singapore, the Philippines and Laos (Tee, 2009). Conversely, all countries allow nutrient content, nutrient comparative and nutrient function claims to be made on the food label.

\section{Benefits and Challenges of Harmonising Food Standards}

Food standards harmonization is an effective way of promoting public health and international food trade. Through harmonization, FAO, WHO and WTO envisage fewer barriers to trade and freer movement of food products among countries (FAO/WHO, 2006; WTO, 2007). In other words, harmonization of standards enables food companies to adhere to one set of international regulations instead of adjusting to a diverse array of national standards for importing countries (Avery, 1995). Subsequently, the food companies gain access to new markets and opportunities for trade, while governments benefit from the economic gains which flow to the food industry from increased trade.

Moreover, global harmonization of food legislation provides many benefits to consumers. For example, it adds to the variety of food available in many parts of the world; thus contributing to the pleasure of eating and food security. It also makes nutrition information on product packaging uniform which allows easy comparison and choice of products. In this way, harmonization of food legislation contributes toward better diets and a reduction in diet-related diseases, such as coronary heart disease, diabetes, stroke and cancer. Generally, the benefits of reduced morbidity are two-fold. First, it reduces medical costs and deaths, which free up household expenditures, and help families redirect resources to other problem areas.

Second, it boosts the labor supply and productivity, and subsequently contributes to family incomes and economic growth (CIE, 2002; Lindenmayer, 1999). As an example, the United States has recorded a significant reduction in cardiovascular diseases since 1970's as a result of better diets (low fat and salt intake) and healthier lifestyles owing to reading of product information by consumers. Consequently, for every dollar of income saved through prevention of death from these diseases there is an economy-wide gain of $\$ 1.92$ (CIE, 2002).

In reality, however, embracing harmonization of food labeling regulations brings along new challenges to many countries and regions of the world. These include legislation which needs updating, establishment of sufficient and efficient accredited laboratories, redesigning food packaging, strengthening administrative infrastructures and human resources, ensuring effective collaboration and information sharing among stakeholders, and, ultimately, efficient monitoring, surveillance and enforcement of the adopted standards (Othman, 2007). Keep in mind that the extent of the compliance costs to be borne by the food industry depends on the timeframe given to make the necessary adjustments.

The impact of such costs is smaller over the medium term than if the manufacturers had to comply immediately (CIE, 2002).This is because there is a natural evolution in food product lines and changes in packaging as manufacturers develop new products to target trends in the market. Inevitably, some (perhaps nearly all) of these costs are ultimately passed forward to consumers (CIE, 2002). For this reason, consumer participation in issues of food standards is critical. Aside from higher food prices as a result of costs incurred in harmonizing food regulations, globalization of the food trade may result in food safety problems being globalized. In other words, as food may be a vehicle for food-borne pathogens, globalization of food trade may be a mechanism for the spread of food-borne illnesses to consumers in far-flung markets. Indeed, new hazards are continually being identified and many outbreaks have been traced to imported foods, including in countries with sophisticated food control systems. For example, $80-90 \%$ of cases of Salmonellosis, acute diarrhoea as a result of food contamination, have been shown to be imported cases (Motarjemi et al., 2001).

Similarly, the import of beef products was implicated in the outbreak of Bovine Spongiform Encephalopathy in Europe in 1999 (Motarjemi et al., 2001). Table 1 summarizes the benefits and challenges of global harmonization of food labeling legislation to all the stakeholders, namely the governments, food firms and consumers. Lessons learned in other regions, such as European Union and North America, show that the harmonization process is complex and sporadic. Countries are confronted with differing levels of development, capacities and determination which hamper the progress of harmonization. Moreover, harmonization of standards, such as labeling of pre-packaged food, applies to a plethora of products and is meant for a heterogeneous population of consumers (e.g. over 580 million people in Southeast Asia region). Therefore, those reviewing food and nutrition regulations must do so in the light of a future scenario driven by innovations in the food industry and the changing purchasing habits of the modern consumer (Motarjemi et al., 2001). For example, many consumers now buy their food via the internet. These consumers have the same need for clear, essential information as those who shop in their local supermarket. As such, the aim of internationalizing food standards should primarily be to create legislation which is flexible enough to be easily adapted as consumer trends evolve, and wide-reaching in its approach to ensure that there is consistency in the approach to providing information on food (Tuner, 1995). 
Table 1 Benefits and challenges of global harmonization of food regulations

\begin{tabular}{|c|c|c|}
\hline Stakeholder & Benefits & Challenges \\
\hline Consumers & $\begin{array}{l}\text { Nutrition information which is uniform and easy } \\
\text { to use } \\
\text { Increased variety of safe and nutritious food } \\
\text { products } \\
\text { Better food purchasing habits and an } \\
\text { improvement in family diets } \\
\text { A reduction in chronic disease, medical costs and } \\
\text { deaths } \\
\text { Higher labor supply and an increase in family } \\
\text { income }\end{array}$ & $\begin{array}{l}\text { - Cost of harmonizing regulations in terms } \\
\text { of higher food prices } \\
\text { - An increased risk of globalizing food } \\
\text { safety problems such as food-borne } \\
\text { illnesses }\end{array}$ \\
\hline Food companies & $\begin{array}{l}\text { Consistent nutritional profiling criteria and } \\
\text { presentation } \\
\text { Access to new markets and opportunities for trade } \\
\text { Higher product quality as a result of increased } \\
\text { competition } \\
\text { Simplification of import and export procedures } \\
\text { and therefore, a reduction in trade costs } \\
\text { An increase in revenue and profits }\end{array}$ & $\begin{array}{l}\text { - Costs associated with familiarization } \\
\text { with harmonized regulations } \\
\text { - Compliance and implementation cost } \\
\text { - Monitoring and administrative costs }\end{array}$ \\
\hline Government & $\begin{array}{l}\text { Growth in food trade and good economic } \\
\text { performance }\end{array}$ & $\begin{array}{l}\text { - Expenditure in establishing global } \\
\text { labeling standards Increased costs of } \\
\text { enforcement, monitoring and } \\
\text { surveillance of compliance with adopted } \\
\text { standards } \\
\text { - Costs associated with consumer } \\
\text { education }\end{array}$ \\
\hline
\end{tabular}

\section{Conclusion}

Food and nutrition labeling regulations are varied in SAARC countries. The existing variations are of preeminent concern in cross-border food trade and access. For this reason, experts in the region shall draft and finalize guidelines for food safety, which include the common guidelines for the labeling of food stuffs. These Guidelines shall be based on Codex Standards and are meant for member countries to use as benchmarks when preparing or updating national standards. International harmonization of standards allows freer movement of food products among countries and, therefore, helps to open doors to new markets and opportunities for the food industry. Ultimately, increased food trade benefits the governments and consumers. Inevitably, however, international harmonization of food standards brings about several challenges that have to be overcome. These challenges have cost implications that are somewhat unbearable, particularly to developing countries such as those in SAARC region. In spite of this, however, the latent challenges should not negate the benefits that can be drawn from increased trade. There is plenty of scope for meeting the challenges which includes, among other things, embracing a culture of participating in the work of Codex, involving consumers and all stakeholders in issues of food standards, defining clearly the complementary roles of different stakeholders, exploring the experiences of other regions, sharing of information among countries, and taking a step-by-step approach in the implementation of the adopted standards. Similarly, international cooperation, particularly assistance of the industrialized countries to developing countries, is crucial in the globalization of food standards and trade. Most importantly, such assistance needs to be carefully designed and coordinated.

\section{References}

Ali E, Talukder DK. 2009. Preferential Trade among the SAARC Countries: Prospects and Challenges of Regional Integration in South Asia, JOAAG, Vol: 4. No. 1

Association of South East Asia Network (ASEAN). 2005. ASEAN common principles for food control systems. Available from: http://www.aseansec.org/21915.pdf

Avery N. 1995. How TNCs influence global food standards. Third World Network Features, 24 October 1995.

Baltas G. 2001. The effects of nutrition information on consumer choice. Journal of Advertising Research, March/April, 57-63.

Behera NC. 2008. SAARC and Beyond Civil Society and Regional Integration in South Asia. SACEPS, Paper No. 19, South Asia Centre for Policy Studies (SACEPS).

Centre for International Economics (CIE). 2002.Evaluating benefits and costs of food regulation: A scoping study. Canberra.

Cheftel JC. 2004. Food and nutrition labeling in the European Union. Food Chem., 93:531-550.

Codex Alimentarius Commission (CAC). 2008. General standard for the labeling of pre-packaged foods (CODEX STAN 1-1985). Rome.

Codex Alimentarius Commission (CAC). 2009a. Guidelines for use of nutrition and health claims (CAC/GL 23-1997). Rome.

Codex Alimentarius Commission (CAC). 2009b. Guidelines on nutrition labeling (CAC/GL 2-1985). Rome. 
Cowburn G, Stockley L. 2005. Consumer understanding and use of nutrition labeling: a systematic review. Public Health Nutrition, 8: 21-28.

Das DK. 2007. South Asian Free Trade Agreement: Prospects of Shallow Regional Integration. CSGR Working Paper 218/07. Coventry, University of Warwick.

Food and Agriculture Organization (FAO) and World Health Organization (WHO). 2006. Understanding the Codex Alimentarius. 3rd Edition. Rome.

Golan, E., Kuchler, F., Mitchell, L., Greene, C. and Jessup A. (2001), "Economics of Food Labeling", Journal of Consumer Policy, Volume 24, Number 2 / June, 2001. 117-184

Kumar S. 2011. Regulatory Arrangements for Disclosure of Nutritional Information on Food Labels in India. Annual IFAMA World Forum and Symposium on the Road to 2050: Sustainability as a Business Opportunity, Frankfurt, Germany.

Lang T. 2006. Food, the law and public health: three models of the relationship. Public Health, 120:30-41.

Lelieveld H, Keener L. 2007. Global harmonization of food regulations and legislation: the Global Harmonisation Initiative. Trends Food Sci Technol., 18: S15-S9.
Lindenmayer I. 1999. Harmonisation of food regulations and food quality/safety measures based on Codex Standards, Guidelines and Recommendations. Rome.

Motarjemi Y, vanSchothost M, Käferstein F. 2001. Future challenges in global harmonization of food safety legislation. Food Control, 12: 339-346.

Othman NM. 2007. Food safety in Southeast Asia: challenges facing the region. AJAD, 4: 83-92.

Tee ES. 2009. Nutrition labelling and health claims: Codex Guidelines. Available from: http://www.aseansec.org/21915.pdf

Tuner A. 1995. Pre-packed food labelling: past, present and future. Br Food J., 97: 23-31.

World Bank. 2007. World Development Report 2007. Washington DC.

World Trade Organization (WTO). 2007. Legal texts: the WTO Agreements. Geneva.

Zaidi and Bakhtiar Mohammad. 2011. Awareness of Pakistani Consumers towards Nutritional Labeling on Product Packaging in Terms of Buying Behavior. International Journal of Business and Social Science, 3: 7-103. 